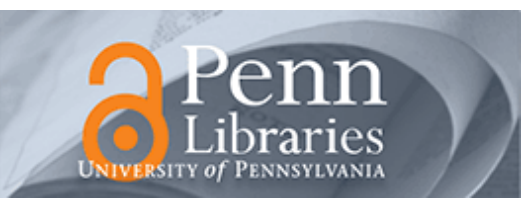

University of Pennsylvania ScholarlyCommons

9-9-2013

\title{
Evaluation and Enhancement of an Intraoperative Insulin Infusion Protocol via In-Silico Simulation
}

\author{
Benjamin A. Kohl \\ University of Pennsylvania Health System, Benjamin.Kohl@uphs.upenn.edu \\ Sanjian Chen \\ University of Pennsylvania, sanjian@cis.upenn.edu \\ Margaret Mullen-Fortino \\ University of Pennsylvania Health System, mrs4tno@gmail.com \\ Insup Lee \\ University of Pennsylvania, lee@cis.upenn.edu
}

Follow this and additional works at: https://repository.upenn.edu/cis_papers

Part of the Computer Engineering Commons, and the Computer Sciences Commons

\section{Recommended Citation}

Benjamin A. Kohl, Sanjian Chen, Margaret Mullen-Fortino, and Insup Lee, "Evaluation and Enhancement of an Intraoperative Insulin Infusion Protocol via In-Silico Simulation", IEEE International Conference on Healthcare Informatics (ICHI 2013) , 307-316. September 2013. http://dx.doi.org/10.1109/ICHI.2013.43

IEEE International Conference on Healthcare Informatics (ICHI 2013), Philadelphia, PA, September 9 - 11, 2013.

This paper is posted at ScholarlyCommons. https://repository.upenn.edu/cis_papers/752

For more information, please contact repository@pobox.upenn.edu. 


\title{
Evaluation and Enhancement of an Intraoperative Insulin Infusion Protocol via In- Silico Simulation
}

\begin{abstract}
Intraoperative glycemic control, particularly in cardiac surgical patients, remains challenging. Patients with impaired insulin sensitivity and/or secretion (i.e., type 1 diabetes mellitus) often manifest extremely labile blood glucose measurements during periods of stress and inflammation. Most current insulin infusion protocols are developed based on clinical experiences and consensus among a local group of physicians. Recent advances in human glucose metabolism modeling have established a computer model that invokes algorithms representing many of the pathways involved in glucose dysregulation for patients with diabetes. In this study, we used an FDA approved glucose metabolism model to evaluate an existing institutional intraoperative insulin infusion protocol via closedloop simulation on the virtual diabetic population that comes with the computer model. A comparison of simulated responses to actual retrospective clinical data from 57 type 1 diabetic patients undergoing cardiac surgery managed by the institutional protocol was performed. We then designed a proportional-derivative controller that overcomes the weaknesses exhibited by our old protocol while preserving its strengths. In-silico evaluation results show that our proportional-derivative controller more effectively manages intraoperative hyperglycemia while simultaneously reducing hypoglycemia and glycemic variability. By performing insilico simulation on intraoperative glucose and insulin responses, robust and seemingly efficacious algorithms can be generated that warrant prospective evaluation in human subjects.
\end{abstract}

\section{Keywords}

Intraoperative glycemic control, in-silico evaluation, proportional-derivative controller, insulin infusion protocol, computer model

\author{
Disciplines \\ Computer Engineering | Computer Sciences
}

\section{Comments}

IEEE International Conference on Healthcare Informatics (ICHI 2013), Philadelphia, PA, September 9 - 11, 2013. 


\title{
Evaluation and Enhancement of an Intraoperative Insulin Infusion Protocol via In-Silico Simulation
}

\author{
Benjamin A. Kohl*, Sanjian Chen ${ }^{\dagger}$, Margaret Mullen-Fortino*, Insup Lee ${ }^{\dagger}$ \\ * University of Pennsylvania Health System \\ Philadelphia, PA 19104, USA \\ Benjamin.Kohl@uphs.upenn.edu,mrs4tno@gmail.com \\ $\dagger$ Department of Computer and Information Science, University of Pennsylvania \\ Philadelphia, PA 19104, USA \\ \{sanjian, lee\}@cis.upenn.edu
}

\begin{abstract}
Intraoperative glycemic control, particularly in cardiac surgical patients, remains challenging. Patients with impaired insulin sensitivity and/or secretion (i.e., type 1 diabetes mellitus) often manifest extremely labile blood glucose measurements during periods of stress and inflammation. Most current insulin infusion protocols are developed based on clinical experiences and consensus among a local group of physicians. Recent advances in human glucose metabolism modeling have established a computer model that invokes algorithms representing many of the pathways involved in glucose dysregulation for patients with diabetes. In this study, we used an FDA approved glucose metabolism model to evaluate an existing institutional intraoperative insulin infusion protocol via closedloop simulation on the virtual diabetic population that comes with the computer model. A comparison of simulated responses to actual retrospective clinical data from 57 type 1 diabetic patients undergoing cardiac surgery managed by the institutional protocol was performed. We then designed a proportional-derivative controller that overcomes the weaknesses exhibited by our old protocol while preserving its strengths. In-silico evaluation results show that our proportional-derivative controller more effectively manages intraoperative hyperglycemia while simultaneously reducing hypoglycemia and glycemic variability. By performing insilico simulation on intraoperative glucose and insulin responses, robust and seemingly efficacious algorithms can be generated that warrant prospective evaluation in human subjects.

Index Terms-Intraoperative glycemic control, in-silico evaluation, proportional-derivative controller, insulin infusion protocol, computer model
\end{abstract}

\section{INTRODUCTION}

Background. Hyperglycemia, unless iatrogenic, typically represents a secondary manifestation (i.e., epiphenomenon) of myriad physiologic, pharmacologic and/or metabolic derangements. While glucose is essential to life, in excess it is associated with increased cardiovascular morbidity and mortality in both diabetics and non-diabetics [1], [2]. Currently, one in every twelve people in the United States has diabetes mellitus and the risk of death among this group is roughly twice that of age-matched controls [3], [4], [5], [6]. It is therefore not surprising that the prevalence of diabetes mellitus and its associated complications among hospitalized patients

This research was supported in part by NSF CNS-1035715 and NIH 1U01EB012470-01. are increasing [7], [8], [9]. While outpatient management of hyperglycemia has historically been the primary focus in this population, and has unquestionably reduced diabetic morbidity and mortality, mounting evidence suggests that inpatient glycemic control may impart a similar benefit [10], [11], [12], [13], [14], [15], [16], [17], [18].

More recent investigations have begun focusing efforts towards reducing hyperglycemia specifically among critically ill and perioperative patients. The primary genesis of this approach stems from a 2001 randomized, controlled study that reported significant decreases in ICU and hospital mortality when blood glucose levels (BGLs) were maintained between $80-100 \mathrm{mg} / \mathrm{dL}$ compared to a less aggressive level of 180 - $200 \mathrm{mg} / \mathrm{dL}$ [19]. Subsequent enthusiasm for aggressive glucose management, however, has tempered as multiple groups attempting to replicate those results were unable to show comparable reductions in morbidity and mortality and have consistently observed high rates of hypoglycemia [20], [21], [22], [23], [24], [25]. Whether the lack of mortality benefit in these studies can be directly attributed to the high rates of hypoglycemia is uncertain. Many groups that have effectively maintained euglycemia whilst avoiding hypoglycemia have demonstrated improved outcomes in those treated more aggressively with insulin [26], [27], [28], [29]. Furthermore, wide and frequent oscillations in plasma glucose (so called, glycemic variability) appear to be as, if not more, important as absolute glucose values in critically ill patients and may compound any deleterious effects of hyperglycemia [30], [31], [32], [33].

While the appropriate target of plasma glucose in critically ill or perioperative patients remains elusive, there is general consensus with regards to three points: 1) Profound and sustained hyperglycemia in critically ill patients is likely harmful; 2) Isolated or sustained hypoglycemia in critically ill patients is likely harmful; 3) Wide and frequent variations in serum glucose values are likely harmful. As these three goals, nebulous as they may be, appear to be recurrent and unifying themes, attention must be directed towards methods, protocols and/or devices that can aid in achieving all three. Until accurate and reliable continuous glucose monitors are 
available for critically ill patients, we remain limited in our ability to measure, respond, and predict future glucose values. Protocols that take into account prior glucose readings and rates of change have been more successful but are far from foolproof [34], [35], [36], [37], [38], [39], [40].

Motivation. Designing a protocol to reliably achieve glucose control, particularly when faced with frequent changes in physiologic parameters such as insulin sensitivity (as is seen perioperatively) is, at best, challenging and, at worst, harmful [41], [42], [43]. Current protocols are mostly derived from experience and intuition and are developed by local consensus, often taking into account available resources. Unlike many engineering systems (e.g., electronic circuits and automobiles), where first-principle plant models can be derived from classical physics, it is extremely difficult to identify a mathematical model that would accurately predict the glucoseinsulin dynamics of an individual with only limited measurable clinical data [44]. Furthermore, it is neither feasible nor ethical to test all potential insulin protocols in human patients.

While attempts to model glucose metabolism using computer simulation were first proposed in the 1960s, newer simulations that incorporate data-driven plant modeling of glucose metabolism now exist and are able to more accurately mimic gluco-regulation in diabetic patients [45], [46], [47]. System identification, a variant of classical plant modeling, incorporates observed "real person" data (input and output of the plant) into a dynamic system allowing one to develop new mathematical models representative of the data entered [48]. Repeated evaluations of numerous insulin infusion protocols, all slightly different, on live patients is neither realistic nor feasible. In-silico evaluation and simulation is a well accepted and validated means to examine a large number of iterative changes and is only recently being used to evaluate insulin infusion protocols [49].

Contributions. The contribution of this paper is twofold. First, we use the Type 1 Diabetes Metabolic (T1DM) Simulator to evaluate an institutional intraoperative insulin protocol (IIP) for our diabetic cardiac surgery patient population and reveal its weaknesses by closed-loop in-silico simulation on the virtual population that comes with the simulator. We compare the simulated glucose responses to the actual retrospective clinical data collected from 57 type 1 diabetic patients undergoing cardiac surgery managed by the IIP, and show that the in-silico simulation is able to closely reproduce the glucose variability observed in the real clinical data. Second, we develop a novel proportional-derivative (PD) algorithm for the target population, propose a parameter tuning method to identify the optimal controller setting, evaluate its performance by in-silico simulations and show that the PD algorithm overcomes the weaknesses of IIP by reducing hypoglycemia and glucose variability, while preserving the strengths of the IIP by keeping most glucose readings within the target range. Our work demonstrates that in-silico simulation is a cost and time effective means of evaluating existing insulin infusion algorithms and generating more efficacious ones that warrant prospective evaluation in clinical trials.

\section{OUR APPROACH}

This section presents our in-silico simulation based approach for evaluating and improving the IIP. We first introduce the software platform for in-silico simulation. Then we describe the IIP and explain how it is evaluated on a virtual population as well as how the simulated results are validated against real clinical data. After evaluating the IIP and identifying its weaknesses, we design a PD algorithm and tune its parameters according to several performance metrics that are clinically important.

\section{A. In Silico Testing Platform}

The T1DM Simulator is a software package that was developed in MATLAB/Simulink ${ }^{\circledR}$ [50]. The patient glucose model that it utilizes is based on a previously published high-dimensional, non-linear differential equation model [51], [52]. The T1DM Simulator (academic version) was provided with 10 pre-identified type 1 diabetic "virtual" adult subjects. Each virtual subject is a configuration of the patient-specific parameters that are used by the simulation model (e.g., body weight and insulin/glucose transportation rates among different body compartments). Many of these parameters cannot be directly identified from the clinical data that hospitals currently have (e.g., total insulin/glucose distribution volumes). The virtual population in the software was identified based on real data collected from a group of individuals who participated in a triple-tracer meal study [52]: the meals were marked with isotope tracers so that the glucose/insulin fluxes in the body can be directly measured. In 2008, the T1DM Simulator (together with its group of 300 virtual subjects) received FDA approval for computer simulations that could be substituted for animal trials in pre-clinical testing and has become an accepted method of evaluation for studies in patients with type 1 diabetes mellitus [53].

The simulator is a Simulink ${ }^{\circledR}$ model file within MATLAB ${ }^{\circledR}$ that includes the patient model, glucose sensor and insulin pump models, and an interface for user-defined controllers [54]. We implemented the control algorithms in Simulink using the Stateflow ${ }^{\circledR}$ toolbox.

\section{B. Evaluation of Insulin Infusion Protocol (IIP) and Valida- tion of the Virtual Population}

After obtaining acknowledgment from the University of Pennsylvania Institutional Review Board (IRB), blood glucose measurements were retrospectively evaluated on 57 type 1 diabetic patients controlled with the IIP during the period of cardiopulmonary bypass. The IIP used in the real patient population was a paper-based protocol that consisted of two parts: 1) a table that categorized the BGL into a finite number of intervals and, based upon the current interval, set a fixed intravenous bolus and infusion rate; 2) a set of infusion rate adjustment rules that took into account the relative change in BGL with respect to the previous value (Figure 1). The target BGL defined by the IIP was $70-130 \mathrm{mg} / \mathrm{dL}$. The protocol rules were entered and evaluated in-silico on 10 virtual patients and the experiments were repeated with different initial BGL 
Initiation of Protocol

Initiate protocol if any one of the following criteria exist:

- Previous diagnosis of diabetes mellitus

- $\quad$ Any blood glucose $(\mathrm{BG})>120 \mathrm{mg} / \mathrm{dL}$

Any patient arriving to operating room on I.V. Insulin

- Anticipated administration of steroids

- Planned circulatory arrest

* INSULIN Bolus / Infusion Protocol *

\begin{tabular}{|c|c|c|}
\hline \begin{tabular}{c|c|} 
Blood Glucose \\
(mg/dL)
\end{tabular} & $\begin{array}{c}\text { Insulin Bolus (U)* } \\
\text { (No bolus pre-CPB) }\end{array}$ & Insulin Infusion (U/h) \\
\hline$<100$ & 0 & 0 \\
\hline $100-110$ & 0 & 2 \\
\hline $111-130$ & 0 & 4 \\
\hline $131-150$ & 2 & 6 \\
\hline $151-170$ & 4 & 8 \\
\hline $171-190$ & 4 & 8 \\
\hline $211-210$ & 6 & 10 \\
\hline $231-230$ & 8 & 10 \\
\hline $251-300$ & 10 & 14 \\
\hline$>300$ & 12 & 15 \\
\hline & 15 & \\
\hline & & \\
\hline
\end{tabular}

INSULIN TITRATION PROTOCOL (start after INITIATING insulin infusion)

* If BG unchanged- repeat action on Infusion Protocol *

\begin{tabular}{|c|c|}
\hline$\frac{\text { Blood Glucose }}{(\mathrm{mg} / \mathrm{dL})}$ & Action \\
\hline$<60$ & $25 \mathrm{~mL}$ of $\mathrm{D}_{50}$ I.V. AND STOP ALL INSULIN \\
\hline $60-99$ & $\begin{array}{l}\text { - If } \mathrm{BG} \downarrow \text { by } 30 \mathrm{mg} / \mathrm{dL} \text { or less from last } \mathrm{BG} \text {, stop infusion } \\
\text { - } \quad \text { If } \mathrm{BG} \downarrow \text { by greater than } 30 \mathrm{mg} / \mathrm{dL} \text { from last } \mathrm{BG}, 25 \mathrm{~mL} \text { of } \mathrm{D}_{50} \mathrm{I} . \mathrm{V} \text {. } \\
\text { - } \quad \text { If } \mathrm{BG} \uparrow \text { from last } \mathrm{BG}, \mathrm{NO} \text { infusion and } \mathrm{NO} \text { bolus }\end{array}$ \\
\hline $100-150$ & $\begin{array}{l}\text { BG Less than Prior } \\
\bullet \quad \text { If BG } \downarrow \text { by } 30 \mathrm{mg} / \mathrm{dL} \text { or less from last BG, } \downarrow \text { infusion by } 2 \mathrm{U} / \mathrm{h} \text { and NO bolus } \\
\text { • If BG } \downarrow \text { by greater than } 30 \mathrm{mg} / \mathrm{dL} \text { from last } \mathrm{BG}, \downarrow \text { infusion by } 4 \mathrm{U} / \mathrm{h} \text { and NO bolus } \\
\text { BG Greater than Prior } \\
\qquad \quad \text { If BG } \uparrow \text { by } 10 \mathrm{mg} / \mathrm{dL} \text { or less from last BG, continue infusion with } 1 / 2 \text { bolus } \\
\text { - If BG } \uparrow \text { by greater than } 10 \mathrm{mg} / \mathrm{dL} \text { from last } \mathrm{BG}, \text { continue per infusion protocol }\end{array}$ \\
\hline $151-170$ & $\begin{array}{l}\text { BG Less than Prior } \\
\text { - If } \mathrm{BG} \downarrow \text { by } 30 \mathrm{mg} / \mathrm{dL} \text { or less from last } \mathrm{BG} \text {, continue per infusion protocol, NO bolus } \\
\text { - If BG } \downarrow \text { by greater than } 30 \mathrm{mg} / \mathrm{dL} \text {, start } 1 / 2 \text { recommended infusion, NO bolus } \\
\text { BG Greater than Prior } \\
\begin{array}{l}\text { - If } \mathrm{BG} \uparrow \text { by } 10 \mathrm{mg} / \mathrm{dL} \text { or less from last } \mathrm{BG} \text {, continue per infusion protocol with } 1 / 2 \text { bolus } \\
\text { - If } \mathrm{BG} \uparrow \text { by greater than } 10 \mathrm{mg} / \mathrm{dL} \text { from last } \mathrm{BG} \text {, continue per infusion protocol }\end{array}\end{array}$ \\
\hline $171-200$ & 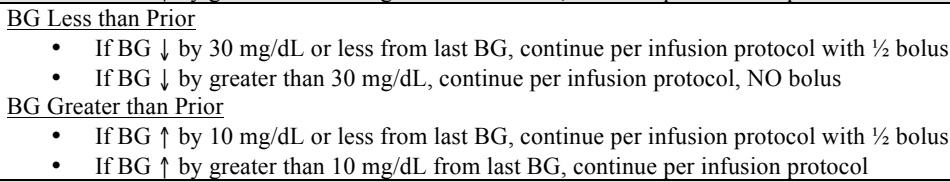 \\
\hline $201-250$ & $\begin{array}{l}\text { BG Less than Prior } \\
\text { - If BG } \downarrow \text { by } 30 \mathrm{mg} / \mathrm{dL} \text { or less from last BG, continue per infusion protocol with } 1 / 2 \text { bolus } \\
\text { - If BG } \downarrow \text { by greater than } 30 \mathrm{mg} / \mathrm{dL} \text {, continue per infusion protocol, NO bolus } \\
\text { BG Greater than Prior } \\
\begin{array}{l}\text { - If BG } \uparrow \text { by } 10 \mathrm{mg} / \mathrm{dL} \text { or less from last BG, continue per infusion protocol with } 1 / 2 \text { bolus } \\
\text { - If BG } \uparrow \text { by greater than } 10 \mathrm{mg} / \mathrm{dL} \text { from last BG, continue per infusion protocol }\end{array}\end{array}$ \\
\hline $251-300$ & 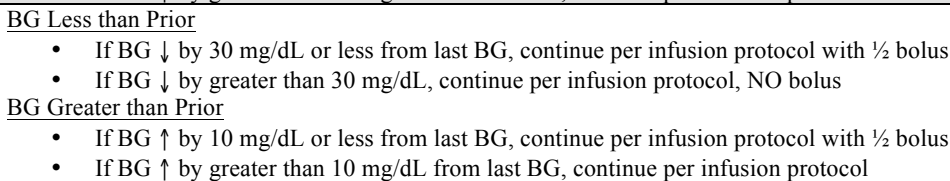 \\
\hline$>300$ & Continue per infusion protocol \\
\hline
\end{tabular}

Fig. 1. Insulin infusion protocol used for real patient population ( $\mathrm{n}=57)$. Abbreviations: BG, Blood glucose; CPB, Cardiopulmonary bypass; D50, 50 percent Dextrose $(50$ gram/100 $\mathrm{mL})$.

values to more thoroughly investigate protocol performance. Blood glucose measurements were taken every 30 minutes (as defined in the IIP). For each real patient's measured BGL trajectory, we ran closed-loop simulation on the 10 virtual subjects starting from the same initial BGL and picked the virtual subject whose simulated BGL trajectory best matched (i.e., had the lowest maximum deviation from) the measured BGLs. Simulated BGL data was then compared with the actual BGL data measured.
When evaluating the control algorithms (the IIP and PD controller) on the in-silico population, the simulation time length for each in silico experiment was 24 hours. While the typical cardiac surgical procedure usually takes only $3-4$ hours, running the simulation for longer periods revealed the "stable" control pattern. A pattern typical of all controllers is an initial variability around the set target prior to stability. It is essential to evaluate for an extended period of time to ensure prolonged stability, enabling a steady state error to 
eventually be applied. Each BGL trajectory was then divided into two epochs: $0-5$ hours ("initial" phase) and $12-24$ hours ("oscillating" phase).

In addition to comparing the mean and standard deviation of the per-subject BGL values, we calculated the normalized glucose liability index (NGLI, $[\mathrm{mg} / \mathrm{dL}]^{2} /$ hour $^{2}$ ), akin to the weekly glucose liability index (GLI) previously published [55]. The GLI $\sum_{i=1}^{N(\text { of } 1 \text { week) }} \frac{\left(G l u_{i+1}-G l u_{i}\right)^{2}}{T_{i+1}-T_{i}}$ is a measure of the weekly sum of the rate of change of BGL, where Glu is the $\mathrm{i}$-th glucose reading $(\mathrm{mg} / \mathrm{dL})$ taken at time $T_{i}$. Because the length of surgery is different for each patient, the GLI must be normalized to the total length of the measurement time, $T_{N}-T_{1}$, where $\mathrm{N}$ is the total number of glucose values obtained for the patient (dependent on the length of surgery), $T_{N}$ is the final time of the measurement period and $T_{1}$ is the initial time. We define this normalized metric as the NGLI. The NGLI was thus calculated as follows:

$$
N G L I=\frac{\sum_{i=1}^{N} \frac{\left(G l u_{i+1}-G l u_{i}\right)^{2}}{T_{i+1}-T_{i}}}{T_{N}-T_{1}}
$$

A higher NGLI implies that the BGL trajectory exhibits more variability.

\section{Proportional Derivative (PD) Controller Design}

After evaluating the weaknesses and strengths of the IIP in silico, we designed a PD controller, which belongs to the broad category of well-known proportional-integral-derivative (PID) controllers (Figure 2). The controller was designed so that the sampling period would be the same as the IIP (30 minutes) and only the calculation method of insulin and dextrose dose would change. Similar to the IIP, the PD controller only makes use of the current and previous BGL readings so that caregivers do not have to collect any additional information in order to evaluate the PD controller in real clinical environment. In our future work we will investigate whether the performance can be further enhanced by adding the integral control, which requires keeping log of all past BGLs. For safety purposes, we retained the same fixed actions of the IIP if and when the BGL reached an extreme (e.g., BGL $<60 \mathrm{mg} / \mathrm{dL}$ or BGL $>300 \mathrm{mg} / \mathrm{dL})$. The critical part of our controller design is that when the BGL is in the control zone $(60-300 \mathrm{mg} / \mathrm{dL})$, the intravenous insulin infusion rate is calculated and changed in response to a proportional-derivative law, where $K_{P}, K_{D}$, Target, and $R_{B}$ are the proportional gain (U/hr per $\mathrm{mg} / \mathrm{dL}$ ), derivative gain $(\mathrm{U} / \mathrm{hr}$ per $\mathrm{mg} / \mathrm{dL})$, target value $(\mathrm{mg} / \mathrm{dL})$, and basal insulin rate (U/hr), respectively. Since one cannot administer "negative" insulin, when the rate (calculated by the PD) is less than zero, we set the rate to zero. Additionally, if BGL drops too fast (defined as: $B G L(n)-B G L(n-1)<-30$ ) and the current BGL(n) is already below $100 \mathrm{mg} / \mathrm{dL}$, we stop the insulin infusion and give intravenous dextrose to counteract impending hypoglycemia. The amount of dextrose $\left(D_{50}\right)$ administered is proportional to the magnitude of BGL decrease using the derivative law.

\section{Proportional Derivative (PD) Controller Tuning}

All controllers require manipulation of the independent variables such that performance, however it is defined, can be optimized (tuning). For this study we picked three performance metrics to monitor and optimize: 1) percentage of BGL values in-target $(70-130 \mathrm{mg} / \mathrm{dL}), 2)$ percentage of BGL values lower than target $(<70 \mathrm{mg} / \mathrm{dL})$, and 3) NGLI. These represent the quality of target tracking, hypoglycemia risk control, and variability minimization, respectively. Additionally, from a clinical standpoint, when tuning the controller we considered hypoglycemia to be the primary safety concern. Thus, if a trade-off had to be made between very low BGL and higher than target BGL, we favored the latter.

There are classic control theory methods that allow one to analytically calculate the optimal PID controller setting based on the mathematical model of the control plant (i.e., the patient model). However, it is very challenging to apply the analytical methods to the patient simulator we were using, because the underlying plant model is highly nonlinear (most classic control approaches assume linear plant models) and many model variables cannot be directly measured in real time on general patients (the tracer experiment used to identify the virtual subjects is clearly too resource demanding to be applied to all ICU patients). Therefore, we tune the controller parameters based on numerical simulations. To identify the optimal setting of the PD controller parameters, we systematically changed $K_{P}, K_{D}$, and $R_{B}$ on a wide range of values and examined how the performance metrics were affected by different controller settings. The optimal setting of $K_{P}, K_{D}$, and $R_{B}$ is the one such that the three performance metrics (intarget percentage, lower-than-target percentage, and NGLI) are optimized.

\section{EXPERIMENTAL RESULTS}

This section enumerates the experimental results of the IIP evaluation, virtual population validation, PD control parameter tuning, and performance comparison between the PD algorithm and the IIP. In the next section, we will further analyze the experimental data and discuss the results in the clinical context.

\section{A. Virtual Population Validation and IIP Evaluation}

The summative data for validation of the virtual subjects can be seen in Table I. This represents the effect of the IIP on the virtual patients compared with the retrospectively observed data in the actual 57 patients. By adjusting the initial BGL in all 10 virtual patients, we evaluated the efficacy of the IIP in-silico. Key metrics of the simulated BGL trajectories on the 10 virtual subjects in response to the IIP are shown in Table II. For each initial BGL, a simulation run generates 10 BGL trajectories (from 10 virtual subjects) and metrics are reported for the initial $(0-5$ hours $)$ phase and the oscillating (12 - 24 hours) phase. 


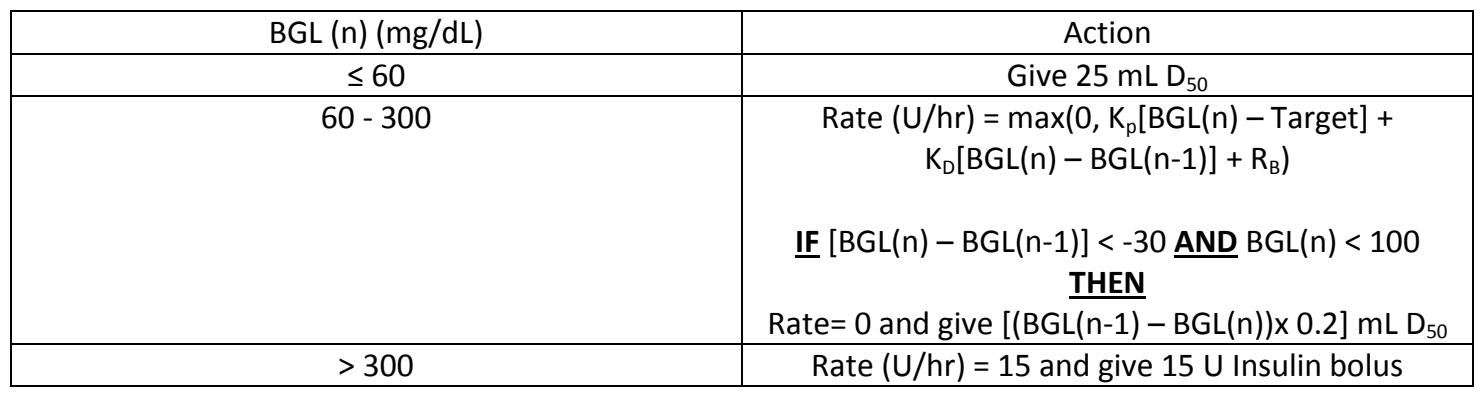

Fig. 2. Proportional-Derivative algorithm for controlling blood glucose intraoperatively. Abbreviations: BGL Blood glucose level; U Units; D50 50 percent Dextrose $(50 \mathrm{~g} / 100 \mathrm{~mL}) ; \mathrm{BGL}(\mathrm{n})$ current blood glucose reading; BGL(n-1) previous blood glucose reading; $K_{P}$ Proportional gain (U/hr per mg/dL; after tuning= 0.05); $K_{D}$ Derivative gain $(\mathrm{U} / \mathrm{hr}$ per $\mathrm{mg} / \mathrm{dL}$; after tuning=0.06); Target Blood glucose target (set to $100 \mathrm{mg} / \mathrm{dL}) ; R_{B}$ Basal insulin rate $(\mathrm{U} / \mathrm{hr}$; after tuning=1.0).
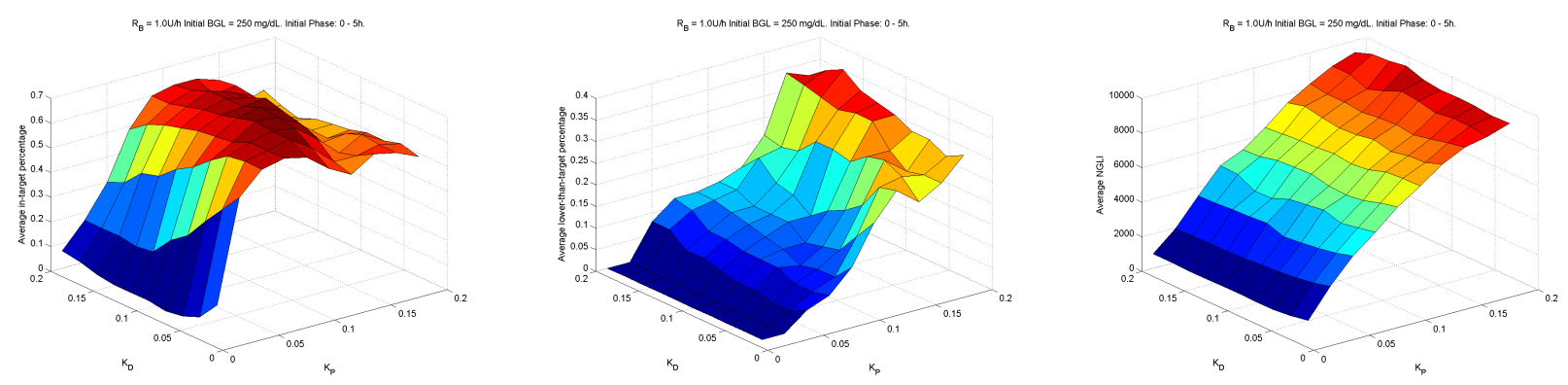

(a) Initial $(0-5 \mathrm{hr})$ phase. $R_{B}=1.0 \mathrm{U} / \mathrm{hr}$ and (b) Initial $(0-5 \mathrm{hr})$ phase. $R_{B}=1.0 \mathrm{U} / \mathrm{hr}$ and (c) Initial $(0-5 \mathrm{hr}) \mathrm{phase}$. $R_{B}=1.0 \mathrm{U} / \mathrm{hr}$ and initial $\mathrm{BGL}=250 \mathrm{mg} / \mathrm{dL}$. Metric $=$ in-target $(70$ initial $\mathrm{BGL}=250 \mathrm{mg} / \mathrm{dL}$. Metric $=$ lower-than - initial $\mathrm{BGL}=250 \mathrm{mg} / \mathrm{dL}$. Metric $=\mathrm{NGLI}$. $-130 \mathrm{mg} / \mathrm{dL}$ ) percentage. target $(<70 \mathrm{mg} / \mathrm{dL})$ percentage.
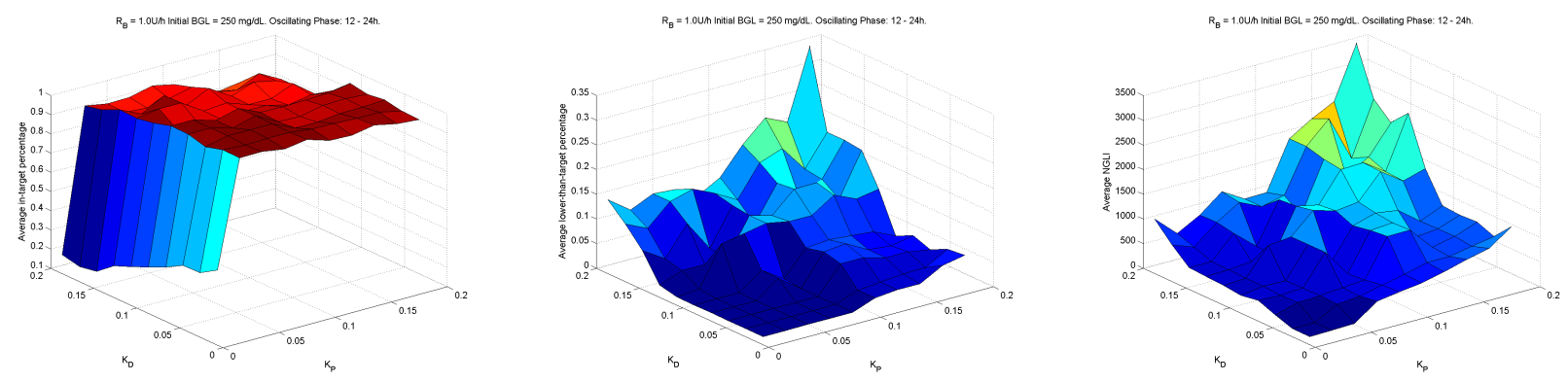

(d) Oscillating (12 - $24 \mathrm{hr}$ ) phase. $R_{B}=1.0 \mathrm{U} / \mathrm{hr}$ (e) Oscillating ( $12-24 \mathrm{hr}$ ) phase. $R_{B}=1.0 \mathrm{U} / \mathrm{hr}$ (f) Oscillating $(12-24 \mathrm{hr})$ phase. $R_{B}=1.0 \mathrm{U} / \mathrm{hr}$ and initial $\mathrm{BGL}=250 \mathrm{mg} / \mathrm{dL}$. Metric $=$ in-target and initial $\mathrm{BGL}=250 \mathrm{mg} / \mathrm{dL}$. Metric $=$ lower- and initial $\mathrm{BGL}=250 \mathrm{mg} / \mathrm{dL}$. Metric $=\mathrm{NGLI}$. $(70-130 \mathrm{mg} / \mathrm{dL})$ percentage. than-target $(<70 \mathrm{mg} / \mathrm{dL})$ percentage.

Fig. 3. Impact of $K_{P}$ and $K_{D}$. Abbreviations: $K_{P}$ Proportional gain (U/hr per mg/dL); $K_{D}$ Derivative gain (U/hr per mg/dL); $R_{B}$ Basal insulin rate (U/hr).

\section{B. Proportional Derivative (PD) Controller Tuning}

We chose the target for the controller to be fixed at 100 $\mathrm{mg} / \mathrm{dL}$, which represents a value in the middle of the IIP target range $(70-130 \mathrm{mg} / \mathrm{dL})$ and is also the insulin action start point in the IIP. The impact of incremental changes of $K_{P}$ and $K_{D}$ on our three primary metrics, both for the initial phase ( $0-5$ hours) and oscillating phase (12 - 24 hours) are shown in Figure 3. Simulation results show that $R_{B}$, in its variance range, does not significantly change the shapes of the $K_{P}-K_{D}$ performance surfaces shown in Figure 3, in which $R_{B}=1.0 \mathrm{U} / \mathrm{hr}$. Therefore, we first identified the optimal
$K_{P}-K_{D}$ setting by integrating the three performance metrics discussed in Section II-D. Key findings in this analysis were that hypoglycemia $(<70 \mathrm{mg} / \mathrm{dL})$ and NGLI are minimized when $K_{P}$ and $K_{D}$ are relatively small. The in-target (70-130 $\mathrm{mg} / \mathrm{dL}$ ) percentage is maximized when $K_{P}$ and $K_{D}$ are in the lower middle range (see Figure 3 and Table III). Integrating the data analysis with the performance metrics, we identified the optimal $K_{P}-K_{D}$ setting, $K_{P}=0.05 \mathrm{U} / \mathrm{hr}$ per $\mathrm{mg} / \mathrm{dL}$ and $K_{D}=0.06 \mathrm{U} / \mathrm{hr}$ per $\mathrm{mg} / \mathrm{dL}$, in the region where the peak areas of in-target percentages (Figures 3 (a) and (d)) overlap the low areas of lower-than-target range and NGLI (Figures 3 (b), (c), (e), and (f)). The metrics were then further optimized 

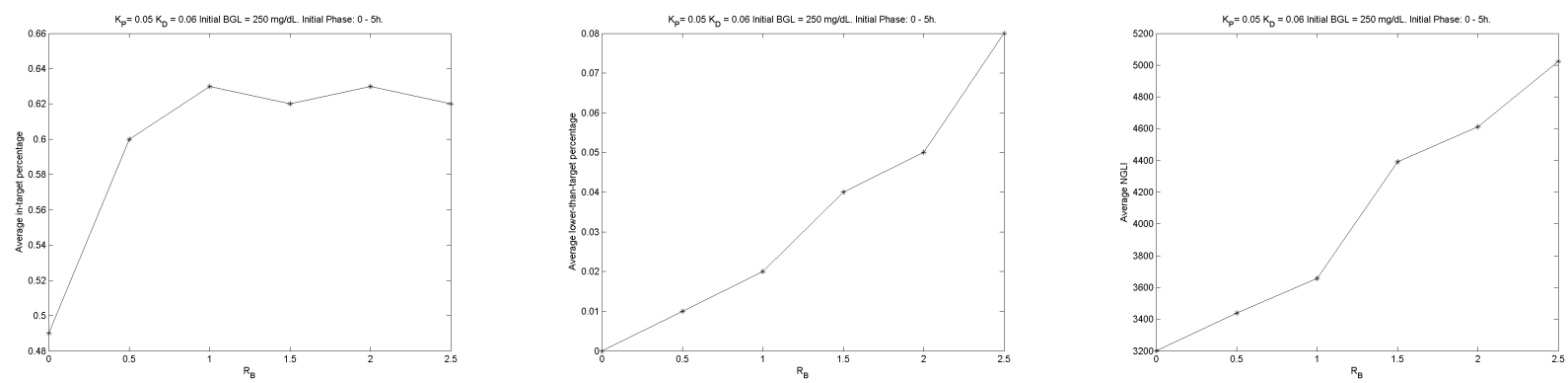

(a) Initial $(0-5 \mathrm{hr})$ phase. Initial BGL $=250$ (b) Initial $(0-5 \mathrm{hr})$ phase. Initial BGL $=250$ (c) Initial $(0-5 \mathrm{hr})$ phase. Initial BGL $=250$ $\mathrm{mg} / \mathrm{dL}$. Metric $=$ In-target $(70-130 \mathrm{mg} / \mathrm{dL})$ per- $\mathrm{mg} / \mathrm{dL}$. Metric $=$ Lower-than-target $(<70 \mathrm{mg} / \mathrm{dL}) \mathrm{mg} / \mathrm{dL}$. Metric= NGLI. centage. percentage.
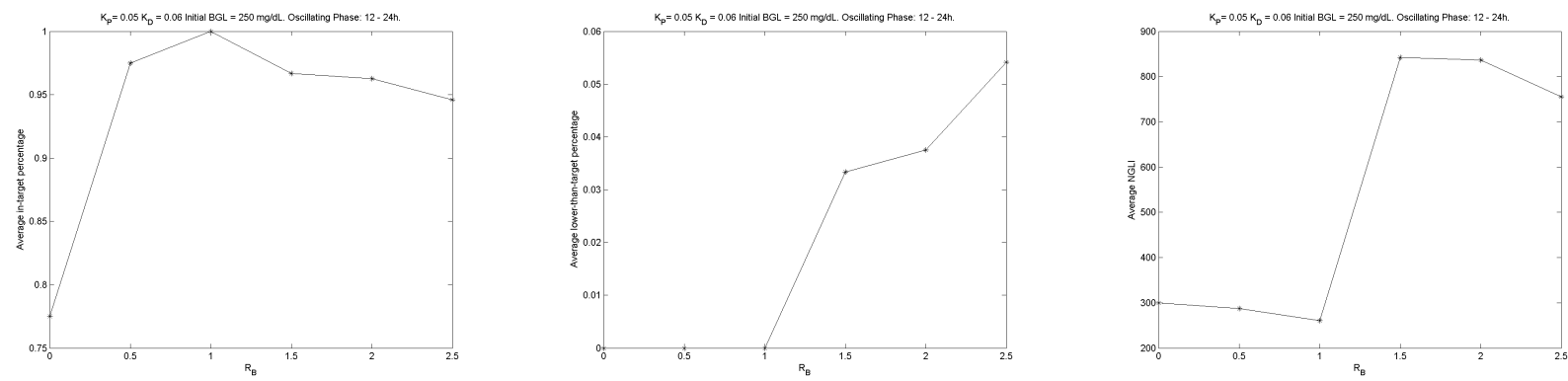

(d) Oscillating $(12-24 \mathrm{hr})$ phase. Initial BGL = (e) Oscillating $(12-24 \mathrm{hr})$ phase. Initial BGL (f) Oscillating $(12-24 \mathrm{hr})$ phase. Initial BGL $=$ $250 \mathrm{mg} / \mathrm{dL}$. Metric $=$ In-target $(70-130 \mathrm{mg} / \mathrm{dL})=250 \mathrm{mg} / \mathrm{dL}$. Metric $=$ Lower-than-target $(<70250 \mathrm{mg} / \mathrm{dL}$. Metric $=$ NGLI. percentage. $\mathrm{mg} / \mathrm{dL})$ percentage.

Fig. 4. Impact of $R_{B}$ on performance metrics after optimal tuning of PD parameters $\left(K_{P}=0.05, K_{D}=0.06\right)$. Abbreviations: $K_{P}$ Proportional gain (U/hr per $\mathrm{mg} / \mathrm{dL}) ; K_{D}$ Derivative gain $(\mathrm{U} / \mathrm{hr}$ per $\mathrm{mg} / \mathrm{dL}) ; R_{B}$ Basal insulin rate $(\mathrm{U} / \mathrm{hr})$.

TABLE I

COMPARISON OF THE EFFECT OF IIP ON BGL IN 10 VIRTUAL PATIENTS IN-SILICO WITH THOSE OF IIP ON BGL IN REAL PATIENTS. ABBREVIATIONS: IIP, INSULIN INFUSION PROTOCOL; STD, STANDARD DEVIATION; BGL, BLOOD GLUCOSE LEVEL; NGLI, NORMALIZED GLUCOSE LABILITY INDEX; NS, NOT SIGNIFICANT. MEAN VALUES WERE COMPARED VIA TWO-TAILED UNPAIRED T-TEST.

\begin{tabular}{|c|c|c|c|}
\hline & Real patients $(\mathrm{n}=57)$ & Virtual patients $(\mathrm{n}=10)$ & $\mathrm{p}$ \\
\hline Average per-subject Mean STD of BGL $(\mathrm{mg} / \mathrm{dL})$ & $130 \pm 16.0$ & $114 \pm 15.3$ & 0.0047 \\
\hline Average per-subject NGLI $\left([\mathrm{mg} / \mathrm{dL}]^{2} / \mathrm{hr}^{2}\right)$ & 1775 & 1782 & $\mathrm{NS}$ \\
\hline
\end{tabular}

by evaluating incremental increases in basal insulin rate $\left(R_{B}\right)$ (Figure 4) according to the same performance metrics and the optimal PD control parameter setting is $K_{P}=0.05 \mathrm{U} / \mathrm{hr}$ per $\mathrm{mg} / \mathrm{dL}, K_{D}=0.06 \mathrm{U} / \mathrm{hr}$ per $\mathrm{mg} / \mathrm{dL}, R_{B}=1.0 \mathrm{U} / \mathrm{hr}$.

\section{Proportional Derivative (PD) Controller Evaluation}

Table IV shows the performance metrics of the PD controller on the virtual population. When comparing the PD controller to the IIP (Table II) there are some notable differences. With regard to target tracking, in the oscillating phase the PD controller is able to maintain close to $100 \%$ of the BGL readings within the target range. In the initial phase, when the BGL starts within the target range $(70-130 \mathrm{mg} / \mathrm{dL})$, the PD controller is able to maintain almost $100 \%$ of BGL values in target. When the BGL starts $>130 \mathrm{mg} / \mathrm{dL}$, the average in-target percentages are similar between the two algorithms. When comparing the risk of hypoglycemia between the IIP and the PD controller, the PD controller is noted to almost completely eliminate occurrences of BGL $<70 \mathrm{mg} / \mathrm{dL}$ in both phases, though this comes with a concomitantly greater frequency of BGL values $>130 \mathrm{mg} / \mathrm{dL}$ in the initial phase compared with the IIP. Furthermore, the average minimum BGL achieved by the PD controller is also significantly higher (but within the target-range), especially for the "extreme" subjects (the min minimum BGL, or lowest minimal BGL) thus further reducing the chance of hypoglycemia. Finally, with regards to BGL variability, the PD controller achieves significantly lower NGLI than the IIP (less than half the variability in both phases for most initial BGLs).

\section{Experimental Data Analysis and Discussion}

\section{A. Validation of the Virtual Population}

By implementing in-silico testing of glycemic control with a validated simulator of diabetes mellitus, we have developed a testable algorithm to be studied in live patients undergoing cardiac surgery. Of note, the T1DM Simulator does not (and cannot) account for all parameters, both in-vivo (i.e., time varying insulin sensitivity) and ex-vivo (i.e., effect of 
TABLE II

KEY METRICS OF SIMULATED BGL CONTROLLED BY THE IIP IN VIRTUAL PATIENTS (N=10)

\begin{tabular}{|c|c|c|c|c|c|c|c|c|c|c|c|c|c|c|}
\hline & \multicolumn{7}{|c|}{ Simulated BGL $(0-5 \mathrm{~h})$} & \multicolumn{7}{|c|}{ Simulated BGL $(12-24 \mathrm{~h})$} \\
\hline $\begin{array}{l}\text { Init BGL } \\
(\mathrm{mg} / \mathrm{dL})\end{array}$ & $\begin{array}{c}\text { Mean BGL } \\
(\mathrm{mg} / \mathrm{dL})^{1}\end{array}$ & $\begin{array}{c}\text { STD of BGL } \\
(\mathrm{mg} / \mathrm{dL})^{1}\end{array}$ & $\begin{array}{c}\text { NGLI } \\
\left([m g / d L]^{2} / h^{2}\right)^{1}\end{array}$ & $70-130^{2}$ & $>130^{2}$ & $<70^{2}$ & $\begin{array}{l}\mathrm{Min} \text { BGL } \\
(\mathrm{mg} / \mathrm{dL})^{1}\end{array}$ & $\begin{array}{l}\text { Mean BGL } \\
(\mathrm{mg} / \mathrm{dL})^{1}\end{array}$ & $\begin{array}{c}\text { STD of BGL } \\
(\mathrm{mg} / \mathrm{dL})^{1}\end{array}$ & $\begin{array}{c}\text { NGLI } \\
\left([m g / d L]^{2} / h^{2}\right)^{1}\end{array}$ & $70-130^{2}$ & $>130^{2}$ & $<70^{2}$ & $\begin{array}{l}\text { Min BGL } \\
(\mathrm{mg} / \mathrm{dL})^{1}\end{array}$ \\
\hline 70 & $86[80,92]$ & $15[9,18]$ & $411[55,1533]$ & $99 \%[90 \%, 100 \%]$ & $0 \%[0 \%, 0 \%]$ & $1 \%[0 \%, 10 \%]$ & $70[66,70]$ & $\begin{array}{l}104[91,108] \\
\end{array}$ & $10[4,29]$ & $882[19,5088]$ & $94 \%[58 \%, 100 \%]$ & $2 \%[0 \%, 17 \%]$ & $4 \%[0 \%, 25 \%]$ & $88[60,101]$ \\
\hline 80 & $93[89,98]$ & $12[9,16]$ & $286[48,1253]$ & $99 \%[90 \%, 100 \%]$ & $0 \%[0 \%, 0 \%]$ & $1 \%[0 \%, 10 \%]$ & $78[63,80]$ & $104[91,108]$ & $10[2,27]$ & $878[9,5083]$ & $92 \%[38 \%, 100 \%]$ & $2 \%[0 \%, 21 \%]$ & $6 \%[0 \%, 42 \%]$ & $89[64,104]$ \\
\hline 90 & $99[97,102]$ & $8[5,19]$ & $216[16,915]$ & $99 \%[90 \%, 100 \%]$ & $1 \%[0 \%, 10 \%]$ & $0 \%[0 \%, 0 \%]$ & $88[78,90]$ & $104[92,108]$ & $10[1,30]$ & $877[4,5045]$ & $94 \%[54 \%, 100 \%]$ & $2 \%[0 \%, 21 \%]$ & $4 \%[0 \%, 25 \%]$ & $87[60,105]$ \\
\hline 100 & $98[88,101]$ & $7[2,15]$ & $318[9,1400]$ & $99 \%[90 \%, 100 \%]$ & $0 \%[0 \%, 0 \%]$ & $1 \%[0 \%, 10 \%]$ & $89[68,98]$ & $104[91,109]$ & $10[1,31]$ & $927[4,5782]$ & $92 \%[42 \%, 100 \%]$ & $2 \%[0 \%, 21 \%]$ & $6 \%[0 \%, 38 \%]$ & $89[59,106]$ \\
\hline 110 & $104[97,107]$ & $6[2,16]$ & $388[10,1781]$ & $99 \%[90 \%, 100 \%]$ & $0 \%[0 \%, 0 \%]$ & $1 \%[0 \%, 10 \%]$ & $95[69,105]$ & $104[91,111]$ & $10[3,31]$ & $951[12,5707]$ & $93 \%[42 \%, 100 \%]$ & $2 \%[0 \%, 21 \%]$ & $5 \%[0 \%, 38 \%]$ & $87[59,100]$ \\
\hline 120 & $102[91,111]$ & $12[5,22]$ & $789[24,3044]$ & $95 \%[80 \%, 100 \%]$ & $0 \%[0 \%, 0 \%]$ & $5 \%[0 \%, 20 \%]$ & $85[60,106]$ & $104[89,109]$ & $10[1,29]$ & $889[8,5030]$ & $93 \%[54 \%, 100 \%]$ & $2 \%[0 \%, 21 \%]$ & $5 \%[0 \%, 25 \%]$ & $88[59,105]$ \\
\hline 130 & {$[96,119]$} & $14[6,25]$ & $928[37,3278]$ & $7 \%[80 \%, 100 \%]$ & $0 \%[0 \%, 0 \%]$ & $3 \%[0 \%, 20 \%]$ & $90[58,112]$ & $104[89,109]$ & & $879[3,4997]$ & $93 \%[46 \%, 100 \%]$ & $2 \%[0 \%, 21 \%]$ & $5 \%[0 \%, 33 \%]$ & $89[59,106]$ \\
\hline 140 & $104[91,117]$ & $17[11,28]$ & $1314[112,4226]$ & $84 \%[60 \%, 90 \%]$ & $11 \%[10 \%, 20 \%]$ & $5 \%[0 \%, 30 \%]$ & $85[53,106]$ & $104[94,109]$ & $10[2,29]$ & $903[10,5411]$ & $94 \%[50 \%, 100 \%]$ & $2 \%[0 \%, 21 \%]$ & $4 \%[0 \%, 29 \%]$ & $89[59,101]$ \\
\hline 150 & $107[93,125]$ & $20[12,31]$ & $1719[129,5728]$ & $81 \%[60 \%, 90 \%]$ & $14 \%[10 \%, 20 \%]$ & $5 \%[0 \%, 30 \%]$ & $87[55,113]$ & $104[91,111]$ & $10[2,31]$ & $962[4,5690]$ & $92 \%[42 \%, 100 \%]$ & $2 \%[0 \%, 21 \%]$ & $6 \%[0 \%, 38 \%]$ & $89[59,103]$ \\
\hline 160 & $5,113]$ & $0,36]$ & $4[415,7501]$ & $80 \%[50 \%, 90 \%]$ & $12 \%[10 \%, 20 \%]$ & $8 \%[0 \%, 40 \%]$ & $74[41,98]$ & $104[91,110]$ & & $921[4,5441]$ & $93 \%[50 \%, 100 \%]$ & $2 \%[0 \%, 21 \%]$ & $5 \%[0 \%, 29 \%]$ & $89[59,106]$ \\
\hline 170 & $87,115]$ & $29[22,38]$ & $2[605,8214]$ & $79 \%[50 \%, 90 \%]$ & $14 \%[10 \%, 20 \%]$ & $7 \%[0 \%, 40 \%]$ & $75[4$ & $104[91,109]$ & & 00105 & $93 \%[50 \%, 100 \%]$ & $2 \%[0 \%, 21 \%]$ & $5 \%[0 \%, 29 \%]$ & $89[59,105]$ \\
\hline 180 & $88,112]$ & $34[27,41]$ & $3[778,8644]$ & $73 \%[50 \%, 80 \%]$ & $17 \%[10 \%, 30 \%]$ & $10 \%[0 \%, 40 \%]$ & $70[38,90]$ & 109] & & $984[8,5315]$ & $95 \%[54 \%, 100 \%]$ & $2 \%[0 \%, 21 \%]$ & $3 \%[0 \%, 25 \%]$ & $89[59,104]$ \\
\hline 190 & $39,119]$ & 36 & $3984[860,9464]$ & $74 \%[50 \%, 80 \%]$ & $17 \%[10 \%, 30 \%]$ & $9 \%[0 \%, 40 \%]$ & $72[39,95]$ & $6,110]$ & 10 & $1049[15,5867]$ & $94 \%[46 \%, 100 \%]$ & $2 \%[0 \%, 21 \%]$ & $4 \%[0 \%, 33 \%]$ & $89[59,105]$ \\
\hline 200 & & & 978] & \%] & $\%]$ & $\%[0 \%, 40 \%]$ & $69[3$ & & & & $93 \%$ & $2 \%[0 \%, 21 \%]$ & & $88[58,103]$ \\
\hline 210 & 10 & 43 & $, 13084]$ & $71 \%$ & $17 \%[10 \%$ & $12 \%[0 \%, 40 \%]$ & & & & 7] & $93 \%$ & $2 \%[0 \%, 21 \%]$ & $5 \%[0 \%, 33 \%]$ & $89[58,105]$ \\
\hline 220 & $9,115]$ & $49[40,56]$ & $1[2065,15537]$ & $65 \%[40 \%, 80 \%]$ & $17 \%[10 \%, 30 \%]$ & $18 \%[0 \%, 40 \%]$ & $57[26,85]$ & 55,109] & 9[ & $868[10,4954]$ & $95 \%[63 \%, 100 \%]$ & $1 \%[0 \%, 13 \%]$ & $3 \%[0 \%, 25 \%]$ & $89[58,106]$ \\
\hline 230 & $105[92,117]$ & $51[43,59]$ & $7[2243,16927]$ & $69 \%[50 \%, 80 \%]$ & $17 \%[10 \%, 30 \%]$ & $14 \%[0 \%, 40 \%]$ & $60[27,88]$ & $105[95,108]$ & $10[1,28]$ & $874[2,4967]$ & $95 \%[63 \%, 100 \%]$ & $1 \%[0 \%, 13 \%]$ & $3 \%[0 \%, 25 \%]$ & $89[58,107]$ \\
\hline 240 & & $55[46,62]$ & 8936] & $63 \%$ & $17 \%[10$ & $20 \%[0 \%, 50 \%]$ & $56[2$ & & $9[2,2$ & $869[13,5005]$ & $94 \%$ & $2 \%[0 \%, 17 \%]$ & $4 \%[0 \%, 21 \%]$ & $91[58,105]$ \\
\hline 250 & $105[91,121]$ & $58[49,65]$ & $10204[3010,21115]$ & $63 \%[40 \%, 80 \%]$ & $17 \%[10 \%, 30 \%]$ & $20 \%[0 \%, 50 \%]$ & $57[24,87]$ & $105[92,109]$ & $9[1,27]$ & $849[6,5005]$ & $95 \%[63 \%, 100 \%]$ & $2 \%[0 \%, 17 \%]$ & $4 \%[0 \%, 21 \%]$ & $90[58,105]$ \\
\hline
\end{tabular}

All data are presented on a per-trajectory basis. Each row represents a starting BGL value and data from 10 trajectories (each virtual patient). ${ }^{1}$ Data represent Mean[Minimum, Maximum]. Target range for IIP was $70-130 \mathrm{mg} / \mathrm{dL} .{ }^{2}$ Values represent Mean $\%$ [minimum \%, maximum \%] BGL within stated range for each trajectory. Abbreviations: BGL, blood glucose level; STD, standard deviation; NGLI, normalized glucose liability index; Min, minimum BGL. Example: when initial BGL is $70 \mathrm{mg} / \mathrm{dL}$ and simulation is run using IIP on the 10 virtual patients, the mean value for the mean BGL of each trajectory (virtual patient) was $86 \mathrm{mg} / \mathrm{dL}$. The virtual patient with the lowest mean had a mean BGL of $80 \mathrm{mg} / \mathrm{dL}$ and the trajectory with the highest mean had a mean of $92 \mathrm{mg} / \mathrm{dL}$. Similar interpretations can be made for the STD BGL, NGLI and Min. Within this same trajectory, the mean \% of BGLs that were within target was 99\%. At the lowest end, 90\% of the BGLs were within target and at the highest end 100\% of the BGLs were within target. Similar interpretations can be made for the $>130$ and $<70 \mathrm{mg} / \mathrm{dL}$ ranges.

TABLE III

OBSERVATIONS NOTED WHEN TUNING THE PD CONTROLLER.

\begin{tabular}{|c|c|c|c|}
\hline PD Parameter & \multicolumn{3}{|c|}{ Metric } \\
\hline & In-target $(70-130 \mathrm{mg} / \mathrm{dL}) \mathrm{BGLs}$ & Less-than-target $(<70 \mathrm{mg} / \mathrm{dL})$ BGLs & NGLI \\
\hline$K_{P}$ & $\begin{array}{l}\text { Initial phase: As } K_{P} \text { increases, metric first increases then decreases } \\
\text { Oscillating phase: As } K_{P} \text { increases, metric decreases (except when } K_{D} \text { is large) }\end{array}$ & $\begin{array}{l}\text { Initial phase: As } K_{P} \text { increases, metric increases } \\
\text { Oscillating phase: As } K_{P} \text { increases, metric increases when } K_{D} \text { is low }\end{array}$ & $\begin{array}{l}\text { Initial phase: As } K_{P} \text { increases, metric increases } \\
\text { Oscillating phase: As } K_{P} \text { increases, metric increases }\end{array}$ \\
\hline$K_{D}$ & $\begin{array}{l}\text { Initial phase: As } K_{D} \text { increases, the peak } K_{P} \text { increases } \\
\text { Oscillating phase: As } K_{D} \text { increases, metric decreases }\end{array}$ & $\begin{array}{l}\text { Initial phase: } K_{D} \text { is not the dominating factor } \\
\text { Oscillating phase: } \mathrm{As} K_{D} \text { increases, metric increases }\end{array}$ & $\begin{array}{l}\text { Initial phase: } K_{D} \text { is not the dominating factor } \\
\text { Oscillating phase: } K_{D} \text { is not the dominating factor }\end{array}$ \\
\hline$R_{B}$ & $\begin{array}{l}\text { Initial phase: metric is maximized when } R_{B} \geq 1 \\
\text { Oscillating phase: metric is maximized when } R_{B} \geq 1\end{array}$ & $\begin{array}{l}\text { Initial phase: As } R_{B} \text { increases, metric increases } \\
\text { Oscillating phase: As } R_{B} \text { increases, metric increases }\end{array}$ & $\begin{array}{l}\text { Initial phase: As } R_{B} \text { increases, metric increases } \\
\text { Oscillating phase: As } R_{B} \text { increases, metric is minimized (when }\end{array}$ \\
\hline
\end{tabular}

Abbreviations: $\mathrm{PD}$, proportional derivative (controller); $K_{P}$, proportional gain $(\mathrm{U} / \mathrm{hr}$ per $\mathrm{mg} / \mathrm{dL}) ; K_{D}$, derivative gain $(\mathrm{U} / \mathrm{hr}$ per $\mathrm{mg} / \mathrm{dL}) ; R_{B}$, basal insulin rate $(\mathrm{U} / \mathrm{hr}) ;$ BGL, blood glucose level; NGLI, normalized glucose liability index $\left[(\mathrm{mg} / \mathrm{dL})^{2} / \mathrm{hr}^{2}\right]$.

cardiopulmonary bypass). As such, one of the limitations of this study is that by evaluating the data from 57 type 1 diabetic patients we may not have identified all variables involved in glucoregulation and insulin dynamics. However, as seen in Table I, the standard deviation of BGL values and normalized glucose lability index (NGLI) of the two groups (virtual and real) were similar. Thus, the virtual population was able to closely reproduce the BGL variability observed in the real data. While the standard deviation and NGLI were quite similar, the per-subject means in the two populations were significantly different. We believe this is due to several reasons. First, the initial "physiological" state of the two populations was mismatched. Each virtual patient needs an initial configuration that includes all physiological states at simulation "time zero" which defines the initial condition for the differential equations that describe the patient model. Most of these physiological states are not directly measurable (i.e., total mass of glucose and insulin in different compartments). In our experiments, these physiological variables were set to be started at a perfectly "stable" state. In other words, given a starting glucose value, the model functions on the premise that the physiological state will not change over time. Mathematically this means that differential equations are solved on the assumption that all derivatives are zero. However, such exquisite homeostasis is unlikely to be present in a real patient at the start of surgery. An additional reason for the observed mean inter-subject variability is that we had a limited quantity of real population data from which we could draw conclusions. Intraoperatively, the BGL was measured at a relatively low frequency (every 30 minutes) and therefore, for each individual patient there were usually fewer than 10 BGL readings over the entire surgery. If the initial states of the two populations are mismatched, the virtual population may not be able to converge to the state of the real patients within such limited time and with such few measurements. Furthermore, while our protocol dictates measuring the BGL every 30 minutes, the reality is that sampling unlikely occurred exactly every 30 minutes in our actual patient population. Finally, we used a relatively small group size for our virtual patient population. The "best match" for each patient could only be chosen from 10 virtual subjects and may not include a good match for each real patient. This would explain why the population standard deviation and NGLI match better than individual data.

\section{B. Performance Comparison between the IIP and the PD algorithm}

Evaluation of the IIP on the 10 virtual subjects is shown in Table II. This data illustrates that during the oscillating phase, the IIP is able to keep most BGLs within the target 
TABLE IV

KEY METRICS OF SIMULATED BGL CONTROLLED BY THE PD CONTROLLER.

\begin{tabular}{|c|c|c|c|c|c|c|c|c|c|c|c|c|c|c|}
\hline & \multicolumn{7}{|c|}{ Simulated BGL $(0-5 \mathrm{~h})$} & \multicolumn{7}{|c|}{ Simulated BGL $(12-24 \mathrm{~h})$} \\
\hline $\begin{array}{l}\text { Init BGL } \\
(\mathrm{mg} / \mathrm{dL})\end{array}$ & $\begin{array}{l}\text { Mean BGL } \\
(\mathrm{mg} / \mathrm{dL})^{1}\end{array}$ & $\begin{array}{c}\text { STD of BGL } \\
(\mathrm{mg} / \mathrm{dL})^{1}\end{array}$ & $\begin{array}{c}\text { NGLI } \\
\left([m g / d L]^{2} / h^{2}\right)^{1}\end{array}$ & $70-130^{2}$ & $>130^{2}$ & $<70^{2}$ & $\begin{array}{l}\text { Min BGL } \\
(\mathrm{mg} / \mathrm{dL})^{1}\end{array}$ & \begin{tabular}{|c|} 
Mean BGL \\
$(\mathrm{mg} / \mathrm{dL})^{1}$
\end{tabular} & $\begin{array}{c}\text { STD of BGL } \\
(\mathrm{mg} / \mathrm{dL})^{1}\end{array}$ & $\begin{array}{c}\text { NGLI } \\
\left([m g / d L]^{2} / h^{2}\right)^{1}\end{array}$ & $70-130^{2}$ & $>130^{2}$ & $<70^{2}$ & $\begin{array}{l}\text { Min BGL } \\
(\mathrm{mg} / \mathrm{dL})^{1}\end{array}$ \\
\hline 70 & $85[79,91]$ & $12[8,16]$ & $76[36,163]$ & $100 \%[100 \%, 100 \%]$ & $0 \%[0 \%, 0 \%]$ & $0 \%[0 \%, 0 \%]$ & $70[70,70]$ & \begin{tabular}{|l}
$110[98,116]$ \\
\end{tabular} & $3[0,14]$ & $255[0,1603]$ & $100 \%[100 \%, 100 \%]$ & $0 \%[0 \%, 0 \%]$ & $0 \%[0 \%, 0 \%]$ & $106[81,116]$ \\
\hline 80 & $91[87,96]$ & $9[6,12]$ & $34[17,56]$ & $100 \%[100 \%, 100 \%]$ & $0 \%[0 \%, 0 \%]$ & $0 \%[0 \%, 0 \%]$ & $80[80,80]$ & $110[99,116]$ & $3[0,15]$ & $230[0,1571]$ & $100 \%[96 \%, 100 \%]$ & $0 \%[0 \%, 4 \%]$ & $0 \%[0 \%, 0 \%]$ & $106[81,116]$ \\
\hline 90 & $95[92,99]$ & $6[3,9]$ & $33[8,114]$ & $100 \%[100 \%, 100 \%]$ & $0 \%[0 \%, 0 \%]$ & $0 \%[0 \%, 0 \%]$ & $89[85,90]$ & $110[98,116]$ & $3[0,15]$ & $271[0,1744]$ & $100 \%[100 \%, 100 \%]$ & $0 \%[0 \%, 0 \%]$ & $0 \%[0 \%, 0 \%]$ & $106[81,116]$ \\
\hline 100 & $99[96,102]$ & $5[1,9]$ & $59[2,252]$ & $100 \%[100 \%, 100 \%]$ & $0 \%[0 \%, 0 \%]$ & $0 \%[0 \%, 0 \%]$ & $93[84,99]$ & $110[98,116]$ & $3[0,15]$ & $258[0,1731]$ & $100 \%[100 \%, 100 \%]$ & $0 \%[0 \%, 0 \%]$ & $0 \%[0 \%, 0 \%]$ & $106[80,116]$ \\
\hline 110 & $103[97,106]$ & $6[3,12]$ & $121[5,546]$ & $100 \%[100 \%, 100 \%]$ & $0 \%[0 \%, 0 \%]$ & $0 \%[0 \%, 0 \%]$ & $95[82,103]$ & $110[98,116]$ & $3[0,15]$ & $258[0,1632]$ & $100 \%[100 \%, 100 \%]$ & $0 \%[0 \%, 0 \%]$ & $0 \%[0 \%, 0 \%]$ & $106[82,116]$ \\
\hline 120 & $106[98,111]$ & $8[6,14]$ & $187[16,744]$ & $100 \%[100 \%, 100 \%]$ & $0 \%[0 \%, 0 \%]$ & $0 \%[0 \%, 0 \%]$ & $96[79,105]$ & $110[98,116]$ & $3[0,15]$ & $271[0,1779]$ & $100 \%[100 \%, 100 \%]$ & $0 \%[0 \%, 0 \%]$ & $0 \%[0 \%, 0 \%]$ & $106[82,116]$ \\
\hline 130 & $109[99,116]$ & $11[8,16]$ & $272[39,905]$ & $100 \%[100 \%, 100 \%]$ & $0 \%[0 \%, 0 \%]$ & $0 \%[0 \%, 0 \%]$ & $97[77,106]$ & $110[98,116]$ & $3[0,14]$ & $246[0,1526]$ & $100 \%[100 \%, 100 \%]$ & $0 \%[0 \%, 0 \%]$ & $0 \%[0 \%, 0 \%]$ & $106[82,116]$ \\
\hline 140 & $112[100,121]$ & $14[12,17]$ & $343[68,963]$ & $83 \%[70 \%, 90 \%]$ & $17 \%[10 \%, 30 \%]$ & $0 \%[0 \%, 0 \%]$ & $98[81,108]$ & $110[98,116]$ & $3[0,15]$ & $267[0,1745]$ & $100 \%[100 \%, 100 \%]$ & $0 \%[0 \%, 0 \%]$ & $0 \%[0 \%, 0 \%]$ & $106[82,116]$ \\
\hline 150 & $115[102,126]$ & $18[15,20]$ & $496[114,1371]$ & $77 \%[60 \%, 90 \%]$ & $23 \%[10 \%, 40 \%]$ & $0 \%[0 \%, 0 \%]$ & $99[80,110]$ & $110[99,116]$ & $3[0,14]$ & $212[0,1484]$ & $100 \%[100 \%, 100 \%]$ & $0 \%[0 \%, 0 \%]$ & $0 \%[0 \%, 0 \%]$ & $107[86,116]$ \\
\hline 160 & $118[103,131]$ & $21[18,24]$ & $662[166,1760]$ & $76 \%[60 \%, 90 \%]$ & $24 \%[10 \%, 40 \%]$ & $0 \%[0 \%, 0 \%]$ & $99[78,111]$ & $110[98,116]$ & $3[0,15]$ & $261[0,1689]$ & $100 \%[100 \%, 100 \%]$ & $0 \%[0 \%, 0 \%]$ & $0 \%[0 \%, 0 \%]$ & $106[83,116]$ \\
\hline 170 & $121[104,135]$ & $25[22,27]$ & $861[237,2211]$ & $72 \%[50 \%, 90 \%]$ & $28 \%[10 \%, 50 \%]$ & $0 \%[0 \%, 0 \%]$ & $99[77,113]$ & $110[99,116]$ & $3[0,15]$ & $245[0,1562]$ & $100 \%[100 \%, 100 \%]$ & $0 \%[0 \%, 0 \%]$ & $0 \%[0 \%, 0 \%]$ & $105[78,116]$ \\
\hline 180 & $123[105,139]$ & $28[25,31]$ & $1095[312,2796]$ & $70 \%[50 \%, 80 \%]$ & $30 \%[20 \%, 50 \%]$ & $0 \%[0 \%, 0 \%]$ & $99[76,114]$ & $110[98,116]$ & $3[0,14]$ & $238[0,1450]$ & $100 \%[100 \%, 100 \%]$ & $0 \%[0 \%, 0 \%]$ & $0 \%[0 \%, 0 \%]$ & $106[81,116]$ \\
\hline 190 & $126[105,144]$ & $32[28,34]$ & $1356[399,3383]$ & $69 \%[40 \%, 80 \%]$ & $31 \%[20 \%, 60 \%]$ & $0 \%[0 \%, 0 \%]$ & $99[74,116]$ & $110[98,116]$ & $3[0,15]$ & $253[0,1600]$ & $100 \%[100 \%, 100 \%]$ & $0 \%[0 \%, 0 \%]$ & $0 \%[0 \%, 0 \%]$ & $106[81,116]$ \\
\hline 200 & $128[106,148]$ & $35[32,38]$ & $1661[504,4129]$ & $68 \%[40 \%, 80 \%]$ & $32 \%[20 \%, 60 \%]$ & $0 \%[0 \%, 0 \%]$ & $98[72,116]$ & $110[98,116]$ & $3[0,15]$ & $253[0,1613]$ & $100 \%[96 \%, 100 \%]$ & $0 \%[0 \%, 4 \%]$ & $0 \%[0 \%, 0 \%]$ & $106[81,116]$ \\
\hline 210 & $131[106,152]$ & $39[35,41]$ & $1997[629,4874]$ & $67 \%[40 \%, 80 \%]$ & $33 \%[20 \%, 60 \%]$ & $0 \%[0 \%, 0 \%]$ & $98[70,117]$ & $110[98,116]$ & $3[0,15]$ & $267[0,1745]$ & $100 \%[100 \%, 100 \%]$ & $0 \%[0 \%, 0 \%]$ & $0 \%[0 \%, 0 \%]$ & $106[82,116]$ \\
\hline 220 & $133[108,156]$ & $43[38,45]$ & $2353[758,5576]$ & $65 \%[40 \%, 80 \%]$ & $34 \%[20 \%, 60 \%]$ & $1 \%[0 \%, 10 \%]$ & $98[69,118]$ & $110[98,116]$ & $3[0,15]$ & $257[0,1641]$ & $100 \%[100 \%, 100 \%]$ & $0 \%[0 \%, 0 \%]$ & $0 \%[0 \%, 0 \%]$ & $105[78,116]$ \\
\hline 230 & $135[108,160]$ & $46[42,48]$ & $2770[904,6468]$ & $64 \%[40 \%, 80 \%]$ & $34 \%[20 \%, 60 \%]$ & $2 \%[0 \%, 10 \%]$ & $97[67,118]$ & $110[98,116]$ & $3[0,15]$ & $249[0,1560]$ & $100 \%[100 \%, 100 \%]$ & $0 \%[0 \%, 0 \%]$ & $0 \%[0 \%, 0 \%]$ & $105[78,116]$ \\
\hline 240 & $, 164]$ & $50[45,52]$ & {$[2,7374]$} & $6,80 \%$ & $35 \%[20 \%, 70 \%]$ & $2 \%[0 \%, 10 \%]$ & $97[65,119]$ & $110[98,116]$ & $3[0,14]$ & $239[0,1467]$ & $100 \%[100 \%, 100 \%]$ & & $\%, 0 \%]$ & $106[82,116]$ \\
\hline 250 & $140[110,167]$ & $53[49,56]$ & $656[1236,8272]$ & $63 \%[30 \%, 80 \%]$ & $35 \%[20 \%, 70 \%]$ & $2 \%[0 \%, 10 \%]$ & $97[64,119]$ & $110[98,116]$ & $3[0,15]$ & $261[0,1675]$ & $100 \%[100 \%, 100 \%]$ & $0 \%[0 \%, 0 \%]$ & $0 \%[0 \%, 0 \%]$ & $105[80,115]$ \\
\hline
\end{tabular}

All data are presented on a per-trajectory basis. Each row represents a starting BGL value and data from 10 trajectories (each virtual patient). ${ }^{1}$ Data represent Mean [Minimum, Maximum]. Target for PD controller was $100 \mathrm{mg} / \mathrm{dL} .{ }^{2}$ Values represent Mean \% [minimum\%, maximum\%] BGL within stated range for each trajectory. Abbreviations: BGL, blood glucose level; STD, standard deviation; NGLI, normalized glucose liability index; Min, minimum BGL. Example: when initial BGL is $70 \mathrm{mg} / \mathrm{dL}$ and simulation is run using the PD controller on the 10 virtual patients, the mean value for the mean BGL of each trajectory (virtual patient) was $85 \mathrm{mg} / \mathrm{dL}$. The virtual patient with the lowest mean had a mean BGL of $79 \mathrm{mg} / \mathrm{dL}$ and the trajectory with the highest mean had a mean of $91 \mathrm{mg} / \mathrm{dL}$. Similar interpretations can be made for the STD BGL, NGLI and Min. Within this same trajectory, the mean \% of BGLs that were within range of $70-130 \mathrm{mg} / \mathrm{dL}$ was $100 \%$. There were no trajectories that fell out of this range. Similar interpretations can be made for the $>130 \mathrm{and}<70 \mathrm{mg} / \mathrm{dL}$ ranges.

range $(70-130 \mathrm{mg} / \mathrm{dL})$ for most subjects. Interestingly, given that the minimum of in-target percentage during this phase is less than $60 \%$ in most runs, it is also apparent that there exist subjects whose BGLs do not track the target well. On the contrary, in the initial phase, the quality of target tracking with IIP is very dependent on the initial BGL. However, when the initial BGL is high, the number of in-target BGLs decrease and the number of below-target $(<70 \mathrm{mg} / \mathrm{dL})$ BGLs increase significantly. This is typical of many currently used insulin infusion protocols and results from the "overshooting" phenomenon. That is, most protocols start with a high dose of insulin bolus and infusion when the initial BGL is high resulting in the subsequent BGL going below the target range. The resultant hypoglycemia is caused by two primary factors: 1) the overshooting during the initial phase, and 2) extreme oscillation in the oscillating phase. In the initial phase, when the initial BGL is $>130 \mathrm{mg} / \mathrm{dL}$, overshooting causes a significant percent (as high as 50\%) of low BGL readings. In the oscillating phase, when considering out-of-target BGL readings, there are more low BGL readings (as high as $42 \%$ ) than high BGL readings. Thus, even when the control pattern stabilizes, the risk of hypoglycemia remains significant with the IIP for some subjects. This is in stark contrast to the performance of the PD controller (Table IV). Similar to the IIP, when initial BGL values were within the target range, the PD controller maintained the majority of BGLs within the target range during the initial phase. However, while both algorithms led to a decrease of in-target BGLs when the initial BGL was $>130 \mathrm{mg} / \mathrm{dL}$, the IIP did so at a cost of significantly increasing the frequency of hypoglycemia (as high as 50\%). No such increase was seen in the PD controller.

The NGLI with the IIP is noted to significantly increase in the initial phase as the initial BGL increases. This is a result of the magnitude and slope of the overshooting. No such relationship is seen in the oscillating phase since the trajectories have stabilized. The average NGLI for the IIP in the initial period was $3466(\mathrm{mg} / \mathrm{dL})^{2} / \mathrm{hr}^{2}$. This translates into an average BGL change of $58.8 \mathrm{mg} / \mathrm{dL}$ per hour. The maximum NGLI was greater than $21,000(\mathrm{mg} / \mathrm{dL})^{2} / \mathrm{hr}^{2}$ which equates to a BGL change of more than $145 \mathrm{mg} / \mathrm{dL}$ per hour. The PD controller, however, very effectively reduced the variability seen with the IIP. In the initial phase, the average NGLI was $1117(\mathrm{mg} / \mathrm{dL})^{2} / \mathrm{hr}^{2}$, which corresponds to a BGL change of $33.4 \mathrm{mg} / \mathrm{dL}$ per hour (a $43 \%$ reduction in variability). The maximum NGLI with the PD controller was $8272(\mathrm{mg} / \mathrm{dL})^{2} / \mathrm{hr}^{2}$. This is $63 \%$ less than the IIP and equates to a BGL change of $91 \mathrm{mg} / \mathrm{dL}$ per hour.

Thus, it appears that the risk of hypoglycemia with our (or any) IIP is significantly increased by two primary mechanisms. The first involves the "overshooting" phenomenon during the initial phase. Indeed, data in Table II show that when the initial BGL is high, overshooting causes a significant percent (as high as $20 \%$ with a maximum of $50 \%$ ) of low BGL readings. The second mechanism of hypoglycemia is by wide variation during the oscillating phase. In the oscillating phase, when considering out of target readings, there is a higher rate of hypoglycemia than hyperglycemia (with the maximum of low BGL percentage being above $40 \%$ ). Thus, for some subjects, the risk of hypoglycemia persists even when the control pattern stabilizes.

Thus, strengths of the IIP during in-silico evaluation included most BGLs being kept within the target range during the "oscillating" phase as well as during the "initial" phase when the starting BGL was within target range. Weaknesses of the protocol include episodes of severe overshooting and oscillations (sometimes large) in BGL trajectory. These oscillations appear to be the result of the discrete nature of the infusion rules in the IIP. That is, because infusion rates are determined by a limited number of adjustment rules, the insulin bolus amount and infusion rate take jumps as the BGL changes. As 
a result, the IIP controller may fail to stabilize an individual at the "equilibrium" state and, instead, oscillate between different infusion values. Finally, the IIP (as a result of overshooting and oscillation) was not very effective at reducing hypoglycemia and BGL variability.

The performance of any PD controller is highly dependent on the accuracy of tuning. Tuning controller parameters on the BGL simulator represents a challenging optimization problem. As explained in Section II-D, it is difficult to apply classic linear system PID tuning theories to the highly complex glucose simulation model. Our strategy in solving this complex nonlinear optimization problem was to systematically characterize the impact of control parameters on performance metrics by running numerical simulations and finding the optimal tradeoff configuration (Figures 3 and 4). One particular challenge with this is the inter-subject variability. While an insulin insensitive subject may favor a more aggressive controller, that same controller may cause significant hypoglycemia in subjects who are highly insulin sensitive. We intentionally designed our algorithm to minimize hypoglycemia over a broad range of glucose trajectories as the optimal controller configuration must achieve good control performance on the larger population.

\section{CONCLUSION}

By utilizing a validated, FDA approved simulator for type 1 diabetes, we evaluated an existing insulin infusion algorithm and developed a novel proportional-derivative algorithm for insulin and dextrose therapy for use during cardiac surgery. The new algorithm emphasizes the strengths of our pre-existing insulin infusion protocol, and minimizes its weaknesses. Most importantly, the PD controller algorithm maximizes the BGL values that are in target range $(70-130 \mathrm{mg} / \mathrm{dL})$, minimizes hypoglycemia $(<70 \mathrm{mg} / \mathrm{dL})$ and minimizes glucose variability. These results warrant further prospective evaluation. We believe our novel PD controller achieves this goal and warrants prospective investigation in-vivo. Furthermore, we have demonstrated that in-silico simulation can be used to assess protocol performance and devise novel algorithms for the intraoperative period.

\section{REFERENCES}

[1] J. S. Krinsley, "Association between hyperglycemia and increased hospital mortality in a heterogeneous population of critically ill patients," Mayo Clin Proc, vol. 78, no. 12, pp. 1471-8, 2003.

[2] K. Malmberg, A. Norhammar, H. Wedel, and L. Ryden, "Glycometabolic state at admission: important risk marker of mortality in conventionally treated patients with diabetes mellitus and acute myocardial infarction: long-term results from the diabetes and insulin-glucose infusion in acute myocardial infarction (digami) study," Circulation, vol. 99, no. 20, pp. 2626-32, 1999.

[3] K. Gu, C. C. Cowie, and M. I. Harris, "Mortality in adults with and without diabetes in a national cohort of the u.s. population, 1971-1993," Diabetes Care, vol. 21, no. 7, pp. 1138-45, 1998.

[4] F. B. Hu, M. J. Stampfer, C. G. Solomon, S. Liu, W. C. Willett, F. E. Speizer, D. M. Nathan, and J. E. Manson, "The impact of diabetes mellitus on mortality from all causes and coronary heart disease in women: 20 years of follow-up," Arch Intern Med, vol. 161, no. 14, pp. 1717-23, 2001.
[5] E. W. Gregg, Q. Gu, Y. J. Cheng, K. M. Narayan, and C. C. Cowie, "Mortality trends in men and women with diabetes, 1971 to 2000," Ann Intern Med, vol. 147, no. 3, pp. 149-55, 2007.

[6] J. Xu, K. Kochanek, S. Murphy, and B. Tejada-Vera, "Deaths: Final data for 2007," National vital statistics reports, vol. 58, no. 19, 2010.

[7] S. Clement, S. S. Braithwaite, M. F. Magee, A. Ahmann, E. P. Smith, R. G. Schafer, and I. B. Hirsch, "Management of diabetes and hyperglycemia in hospitals," Diabetes Care, vol. 27, no. 2, pp. 553-91, 2004.

[8] M. E. Wallymahmed, S. Dawes, G. Clarke, S. Saunders, N. Younis, and I. A. MacFarlane, "Hospital in-patients with diabetes: increasing prevalence and management problems," Diabet Med, vol. 22, no. 1, pp. 107-9, 2005.

[9] C. S. Levetan, M. Passaro, K. Jablonski, M. Kass, and R. E. Ratner, "Unrecognized diabetes among hospitalized patients," Diabetes Care, vol. 21, no. 2, pp. 246-9, 1998.

[10] T. D. Control and C. T. R. Group, "The effect of intensive treatment of diabetes on the development and progression of long-term complications in insulin-dependent diabetes mellitus," N Engl J Med, vol. 329, no. 14, pp. 977-86, 1993.

[11] U. P. D. S. U. Group, "Intensive blood-glucose control with sulphonylureas or insulin compared with conventional treatment and risk of complications in patients with type 2 diabetes (ukpds 33)," Lancet, vol. 352, no. 9131, pp. 837-53, 1998 .

[12] C. Stettler, S. Allemann, P. Juni, C. A. Cull, R. R. Holman, M. Egger, S. Krahenbuhl, and P. Diem, "Glycemic control and macrovascular disease in types 1 and 2 diabetes mellitus: Meta-analysis of randomized trials," Am Heart J, vol. 152, no. 1, pp. 27-38, 2006.

[13] E. H. Baker, C. H. Janaway, B. J. Philips, A. L. Brennan, D. L. Baines, D. M. Wood, and P. W. Jones, "Hyperglycaemia is associated with poor outcomes in patients admitted to hospital with acute exacerbations of chronic obstructive pulmonary disease," Thorax, vol. 61, no. 4, pp. 284 9, 2006.

[14] A. Bruno, D. Gregori, A. Caropreso, F. Lazzarato, M. Petrinco, and E. Pagano, "Normal glucose values are associated with a lower risk of mortality in hospitalized patients," Diabetes Care, vol. 31, no. 11, pp. 2209-10, 2008

[15] F. A. McAlister, S. R. Majumdar, S. Blitz, B. H. Rowe, J. Romney, and T. J. Marrie, "The relation between hyperglycemia and outcomes in 2,471 patients admitted to the hospital with community-acquired pneumonia," Diabetes Care, vol. 28, no. 4, pp. 810-5, 2005.

[16] P. G. Noordzij, E. Boersma, F. Schreiner, M. D. Kertai, H. H. Feringa, M. Dunkelgrun, J. J. Bax, J. Klein, and D. Poldermans, "Increased preoperative glucose levels are associated with perioperative mortality in patients undergoing noncardiac, nonvascular surgery," Eur J Endocrinol, vol. 156, no. 1, pp. 137-42, 2007.

[17] M. H. Murad, J. A. Coburn, F. Coto-Yglesias, S. Dzyubak, A. Hazem, M. A. Lane, L. J. Prokop, and V. M. Montori, "Glycemic control in non-critically ill hospitalized patients: a systematic review and metaanalysis," J Clin Endocrinol Metab, vol. 97, no. 1, pp. 49-58, 2012.

[18] G. E. Umpierrez, R. Hellman, M. T. Korytkowski, M. Kosiborod, G. A. Maynard, V. M. Montori, J. J. Seley, and G. Van den Berghe, "Management of hyperglycemia in hospitalized patients in non-critical care setting: an endocrine society clinical practice guideline," $J$ Clin Endocrinol Metab, vol. 97, no. 1, pp. 16-38, 2012.

[19] G. van den Berghe, P. Wouters, F. Weekers, C. Verwaest, F. Bruyninckx, M. Schetz, D. Vlasselaers, P. Ferdinande, P. Lauwers, and R. Bouillon, "Intensive insulin therapy in critically ill patients," N Engl J Med, vol. 345 , no. 19, pp. 1359-67, 2001.

[20] J. C. Preiser, P. Devos, S. Ruiz-Santana, C. Melot, D. Annane, J. Groeneveld, G. Iapichino, X. Leverve, G. Nitenberg, P. Singer, J. Wernerman, M. Joannidis, A. Stecher, and R. Chiolero, "A prospective randomised multi-centre controlled trial on tight glucose control by intensive insulin therapy in adult intensive care units: the glucontrol study," Intensive Care Med, vol. 35, no. 10, pp. 1738-48, 2009

[21] S. Finfer, D. R. Chittock, S. Y. Su, D. Blair, D. Foster, V. Dhingra, R. Bellomo, D. Cook, P. Dodek, W. R. Henderson, P. C. Hebert, S. Heritier, D. K. Heyland, C. McArthur, E. McDonald, I. Mitchell, J. A. Myburgh, R. Norton, J. Potter, B. G. Robinson, and J. J. Ronco, "Intensive versus conventional glucose control in critically ill patients," N Engl J Med, vol. 360, no. 13, pp. 1283-97, 2009.

[22] F. M. Brunkhorst, C. Engel, F. Bloos, A. Meier-Hellmann, M. Ragaller, N. Weiler, O. Moerer, M. Gruendling, M. Oppert, S. Grond, D. Olthoff, U. Jaschinski, S. John, R. Rossaint, T. Welte, M. Schaefer, P. Kern, E. Kuhnt, M. Kiehntopf, C. Hartog, C. Natanson, M. Loeffler, and 
K. Reinhart, "Intensive insulin therapy and pentastarch resuscitation in severe sepsis," N Engl J Med, vol. 358, no. 2, pp. 125-39, 2008.

[23] Y. M. Arabi, O. C. Dabbagh, H. M. Tamim, A. A. Al-Shimemeri, Z. A Memish, S. H. Haddad, S. J. Syed, H. R. Giridhar, A. H. Rishu, M. O. Al-Daker, S. H. Kahoul, R. J. Britts, and M. H. Sakkijha, "Intensive versus conventional insulin therapy: a randomized controlled trial in medical and surgical critically ill patients," Crit Care Med, vol. 36, no. 12 , pp. $3190-7,2008$.

[24] C. De La Rosa Gdel, J. H. Donado, A. H. Restrepo, A. M. Quintero, L. G. Gonzalez, N. E. Saldarriaga, M. Bedoya, J. M. Toro, J. B. Velasquez, J. C. Valencia, C. M. Arango, P. H. Aleman, E. M. Vasquez, J. C. Chavarriaga, A. Yepes, W. Pulido, and C. A. Cadavid, "Strict glycaemic control in patients hospitalised in a mixed medical and surgical intensive care unit: a randomised clinical trial," Crit Care, vol. 12, no. 5, p. R120, 2008.

[25] F. Bilotta, R. Caramia, F. P. Paoloni, R. Delfini, and G. Rosa, "Safety and efficacy of intensive insulin therapy in critical neurosurgical patients," Anesthesiology, vol. 110, no. 3, pp. 611-9, 2009.

[26] H. L. Lazar, S. R. Chipkin, C. A. Fitzgerald, Y. Bao, H. Cabral, and C. S. Apstein, "Tight glycemic control in diabetic coronary artery bypass graft patients improves perioperative outcomes and decreases recurrent ischemic events," Circulation, vol. 109, no. 12, pp. 1497-502, 2004.

[27] K. Malmberg, "Prospective randomised study of intensive insulin treatment on long term survival after acute myocardial infarction in patients with diabetes mellitus. digami (diabetes mellitus, insulin glucose infusion in acute myocardial infarction) study group," Bmj, vol. 314, no. 7093, pp. 1512-5, 1997.

[28] G. Leibowitz, E. Raizman, M. Brezis, B. Glaser, I. Raz, and O. Shapira, "Effects of moderate intensity glycemic control after cardiac surgery," Ann Thorac Surg, vol. 90, no. 6, pp. 1825-32, 2010.

[29] B. Subramaniam, P. J. Panzica, V. Novack, F. Mahmood, R. Matyal, J. D. Mitchell, E. Sundar, R. Bose, F. Pomposelli, J. R. Kersten, and D. S. Talmor, "Continuous perioperative insulin infusion decreases major cardiovascular events in patients undergoing vascular surgery: a prospective, randomized trial," Anesthesiology, vol. 110, no. 5, pp. 9707, 2009.

[30] M. Egi, R. Bellomo, E. Stachowski, C. J. French, and G. Hart, "Variability of blood glucose concentration and short-term mortality in critically ill patients," Anesthesiology, vol. 105, no. 2, pp. 244-52, 2006.

[31] N. A. Ali, J. O’Brien, J. M., K. Dungan, G. Phillips, C. B. Marsh, S. Lemeshow, J. Connors, A. F., and J. C. Preiser, "Glucose variability and mortality in patients with sepsis," Crit Care Med, vol. 36, no. 8, pp. 2316-21, 2008.

[32] L. A. Dossett, H. Cao, N. T. Mowery, M. J. Dortch, J. Morris, J. M., and A. K. May, "Blood glucose variability is associated with mortality in the surgical intensive care unit," Am Surg, vol. 74, no. 8, pp. 679-85; discussion 685, 2008

[33] J. S. Krinsley, "Glycemic variability: a strong independent predictor of mortality in critically ill patients," Crit Care Med, vol. 36, no. 11, pp. 3008-13, 2008.

[34] S. S. Braithwaite, R. Edkins, K. L. Macgregor, E. S. Sredzienski, M. Houston, B. Zarzaur, P. B. Rich, B. Benedetto, and E. J. Rutherford, "Performance of a dose-defining insulin infusion protocol among trauma service intensive care unit admissions," Diabetes Technol Ther, vol. 8 , no. 4, pp. 476-88, 2006.

[35] S. S. Braithwaite and S. Clement, "Algorithms for intravenous insulin delivery," Curr Diabetes Rev, vol. 4, no. 3, pp. 258-68, 2008.

[36] C. Pachler, J. Plank, H. Weinhandl, L. J. Chassin, M. E. Wilinska, R. Kulnik, P. Kaufmann, K. H. Smolle, E. Pilger, T. R. Pieber, M. Ellmerer, and R. Hovorka, "Tight glycaemic control by an automated algorithm with time-variant sampling in medical icu patients," Intensive Care Med, vol. 34, no. 7, pp. 1224-30, 2008.

[37] S. Meijering, A. M. Corstjens, J. E. Tulleken, J. H. Meertens, J. G. Zijlstra, and J. J. Ligtenberg, "Towards a feasible algorithm for tight glycaemic control in critically ill patients: a systematic review of the literature," Crit Care, vol. 10, no. 1, p. R19, 2006.

[38] R. Shulman, S. J. Finney, C. O'Sullivan, P. A. Glynne, and R. Greene, "Tight glycaemic control: a prospective observational study of a computerised decision-supported intensive insulin therapy protocol," Crit Care, vol. 11, no. 4, p. R75, 2007.

[39] A. Anabtawi, M. Hurst, M. Titi, S. Patel, C. Palacio, and K. Rajamani, "Incidence of hypoglycemia with tight glycemic control protocols: a comparative study," Diabetes Technol Ther, vol. 12, no. 8, pp. 635-9, 2010 .
[40] M. Horibe, B. G. Nair, G. Yurina, M. B. Neradilek, and I. Rozet, "A novel computerized fading memory algorithm for glycemic control in postoperative surgical patients," Anesth Analg, vol. 115, no. 3, pp. 5807, 2012.

[41] A. J. Le Compte, C. G. Pretty, J. Lin, G. M. Shaw, A. Lynn, and J. G. Chase, "Impact of variation in patient response on model-based control of glycaemia in critically ill patients," Comput Methods Programs Biomed, 2011.

[42] J. G. Chase, A. J. Le Compte, F. Suhaimi, G. M. Shaw, A. Lynn, J. Lin, C. G. Pretty, N. Razak, J. D. Parente, C. E. Hann, J. C. Preiser, and T. Desaive, "Tight glycemic control in critical care-the leading role of insulin sensitivity and patient variability: a review and model-based analysis," Comput Methods Programs Biomed, vol. 102, no. 2, pp. 15671, 2011.

[43] S. Finfer, B. Liu, D. R. Chittock, R. Norton, J. A. Myburgh, C. McArthur, I. Mitchell, D. Foster, V. Dhingra, W. R. Henderson, J. J. Ronco, R. Bellomo, D. Cook, E. McDonald, P. Dodek, P. C. Hebert, D. K. Heyland, and B. G. Robinson, "Hypoglycemia and risk of death in critically ill patients," $N$ Engl J Med, vol. 367, no. 12, pp. 1108-18, 2012.

[44] M. Hoekstra, M. Vogelzang, E. Verbitskiy, and M. W. Nijsten, "Health technology assessment review: Computerized glucose regulation in the intensive care unit-how to create artificial control," Crit Care, vol. 13, no. 5 , p. $223,2009$.

[45] R. Hovorka, L. J. Chassin, M. Ellmerer, J. Plank, and M. E. Wilinska, "A simulation model of glucose regulation in the critically ill," Physiol Meas, vol. 29, no. 8, pp. 959-78, 2008.

[46] J. G. Chase, G. M. Shaw, J. Lin, C. V. Doran, C. Hann, T. Lotz, G. C. Wake, and B. Broughton, "Targeted glycemic reduction in critical care using closed-loop control," Diabetes Technol Ther, vol. 7, no. 2, pp. 274-82, 2005.

[47] R. G. Janes and J. O. Osburn, "The analysis of glucose measurements by computer simulation," J Physiol, vol. 181, no. 1, pp. 59-67, 1965.

[48] L. Ljung, "Perspectives on system identification," Annual Reviews in Control, vol. 34, pp. 1-12, 2010.

[49] J. C. Lee, M. Kim, K. R. Choi, T. J. Oh, M. Y. Kim, Y. M. Cho, K. Kim, H. C. Kim, and S. Kim, "In silico evaluation of glucose control protocols for critically ill patients," IEEE Trans Biomed Eng, vol. 59, no. 1, pp. 54-7, 2012.

[50] T.E.Group. Type 1 diabetes metabolic simulator. [Online]. Available: http://tegvirginia.com/solutions/t1dms

[51] C. Dalla Man, R. A. Rizza, and C. Cobelli, "Meal simulation model of the glucose-insulin system," IEEE Trans Biomed Eng, vol. 54, no. 10, pp. 1740-9, 2007.

[52] B. P. Kovatchev, M. Breton, C. D. Man, and C. Cobelli, "In silico preclinical trials: a proof of concept in closed-loop control of type 1 diabetes," J Diabetes Sci Technol, vol. 3, no. 1, pp. 44-55, 2009.

[53] M. W. Percival, Y. Wang, B. Grosman, E. Dassau, H. Zisser, L. Jovanovic, and r. Doyle, F. J., "Development of a multi-parametric model predictive control algorithm for insulin delivery in type 1 diabetes mellitus using clinical parameters," J Process Control, vol. 21, no. 3, pp. 391-404, 2011.

[54] S. D. Patek, B. W. Bequette, M. Breton, B. A. Buckingham, E. Dassau, r. Doyle, F. J., J. Lum, L. Magni, and H. Zisser, "In silico preclinical trials: methodology and engineering guide to closed-loop control in type 1 diabetes mellitus," J Diabetes Sci Technol, vol. 3, no. 2, pp. 269-82, 2009.

[55] E. A. Ryan, T. Shandro, K. Green, B. W. Paty, P. A. Senior, D. Bigam, A. M. Shapiro, and M. C. Vantyghem, "Assessment of the severity of hypoglycemia and glycemic lability in type 1 diabetic subjects undergoing islet transplantation," Diabetes, vol. 53, no. 4, pp. 955-62, 2004. 